\title{
Gramaticalización y diacronía de las perífrasis comenzar a y empezar a + INFINITIVO
}

\author{
Axel Hernández Díaz ${ }^{1}$ \\ Universidad Nacional Autónoma de México, México
}

\begin{abstract}
Resumen
El objetivo de este trabajo es el análisis diacrónico de las perífrasis incoativas comenzar a y empezar $a+$ INF a la luz de la teoría de la gramaticalización, en un intento por contribuir a la historia del español y, particularmente, a los estudios centrados en las perífrasis verbales. A partir de los resultados obtenidos del análisis de un número amplio de ocurrencias documentadas en el periodo comprendido entre los siglos XI al XXI, consideramos la importancia del significado léxico de las palabras en la construcción de piezas gramaticales, puesto que la sinonimia parece jugar un papel importante en la conformación de la gramática de una lengua. Como veremos, la alternancia de las formas estudiadas muestra que las dos conviven actualmente y que su uso está condicionado por factores contextuales y también cronológicos, pues ambas expresan valores semánticos similares, si bien el uso de empezar $a+$ INF se incrementa alrededor del siglo XIX, por lo que reflexionamos sobre otros procesos de cambio vinculados con las perífrasis verbales en este lapso y su importancia en la periodización sintáctica de la lengua española.
\end{abstract}

1 Para correspondencia, dirigirse a: axel.hernandez@comunidad.unam.mx, Facultad de Filosofía y Letras. Universidad Nacional Autónoma de México. Circuito Interior. Ciudad Universitaria, s/n, C.P. 04510, Coyoacán, Ciudad de México, México. 
Palabras clave: perífrasis incoativas, comenzar $a+$ INFINITIVo, empezar a + INFINITIVo gramaticalización, construcciones de soporte, periodización sintáctica del español.

\title{
GRAMMATICALIZATION AND DIACHRONY OF THE PERIPHRASES COMENZAR A AND EMPEZAR A + INFINITIVE
}

\begin{abstract}
This paper provides a diachronic study of the inchoative periphrases comenzar $a$ and empezar $a+$ INFINITIVE drawing upon grammaticalization theory, in an attempt to contribute to the history of Spanish and, particularly, to the studies focused on verbal periphrases. Based on the results of an analysis of a large number of documented occurrences between the $11^{\text {th }}$ and $21^{\text {st }}$ centuries, we propose that the lexical meaning of words to be relevant in the construction of grammatical pieces; therefore synonymy seems to play an important role in shaping the grammar of a language. As we will see, alternation of the studied forms shows that both coexist nowadays, and that their use is conditioned both by contextual and chronological factors, because both express the same semantic values. Since the use of empezar $a+$ INFINITIVE increases around the $19^{\text {th }}$ century, we reflect on other change processes linked to verbal periphrases during this period, and on their importance in the syntactic periodization of Spanish.
\end{abstract}

Keywords: Inchoative periphrases, comenzar a + INFINITIVE, empezar $a+$ INFINITIVE grammaticalization, support constructions, syntactic periodization of Spanish.

Recibido: 09/06/19 Aceptado: 05/08/19 


\section{INTRODUCCIÓN²}

El presente trabajo tiene por objeto el estudio diacrónico de las perífrasis verbales comenzar $a+$ INF y empezar $a+$ INF, con la intención de entender cómo ha sido su proceso de formación y desarrollo en la diacronía de la lengua española. Decidimos estudiarlas de manera conjunta, en tanto que ambas se clasifican como perífrasis aspectuales incoativas; también porque los auxiliares con los que se forman expresan un significado muy similar en sus usos plenos, 'tener principio', 'dar principio (algo)' (RAE, En línea, versión 2018, s.v. comenzar, empezar), y se emplean como sinónimos en una amplia variedad de contextos, si bien su origen etimológico es distinto. No obstante, creemos que sus primeros sentidos y su uso a nivel léxico tienen un impacto que alcanza a las construcciones perifrásticas a las que dan origen.

En los casos que nos competen, comenzar y empezar van seguidos de un infinitivo que se refiere a un evento, introducido por la preposición $a$, lo que supone la modificación argumental del verbo y un cambio semántico en la aspectualidad de las oraciones $(1)^{3}$. En estas ocurrencias, es preciso analizar los verbos comenzar y empezar en conjunto con el infinitivo que les sigue, puesto que el auxiliar y el auxiliado hacen referencia a un único evento, por lo que funcionan como un solo predicado. Como en el resto de las perífrasis modales, temporales y aspectuales, el primer verbo lleva las marcas de tiempo, número y persona y añade el valor aspectual incoativo al verbo en infinitivo. Consideramos perífrasis las formas de (1), aunque no implican la desemantización del primer verbo por completo, ni tampoco erosión fonética-dos de los criterios que se han empleado para caracterizar

2 Agradezco a los proyectos de investigación Diccionario histórico de las perífrasis verbales del español. Gramática, pragmática y discurso del MINECO (FFI2016-77397-P) y Gradia. Grup de Gramàtica i Diacronia (2017 SGR 01337) del AGAUR el apoyo brindado para la realización de este trabajo. La primera versión fue presentada en la UNAM en abril de 2018, en un evento que fue posible, en parte, gracias al apoyo del Programa de Maestría y Doctorado en Lingüística para el que va igualmente un agradecimiento. Mis más sinceras gracias además a los autores que participan en este monográfico, quienes me ayudaron a mejorarlo con sus valiosas sugerencias y lecturas atentas. Igualmente, agradezco a dos evaluadores anónimos sus comentarios y recomendaciones, fundamentales para lograr esta versión final. Los errores son solamente míos.

3 La mayoría de las ocurrencias en las que se basa este trabajo fueron extraídas del corpus GRADIA, como se explicará más adelante, aunque también hemos tomado algunos datos del Corpus diacrónico del Español (CORDE) de la RAE (http://corpus.rae.es/cordenet.html). Para la información puntual al respecto, véase más adelante el §3, la nota 9 y la información bibliográfica sobre las obras del corpus citadas, listadas en orden cronológico al final. 
la gramaticalización (Heine y Kuteva 2007, Lehmann 2015: capítulo 4)- sí suponen un tipo de extensión, en términos de Heine (2003), entendida como la generalización o ampliación de los contextos en que se usa una pieza léxica, dado que los auxiliares aparecen en nuevos contextos sintácticos y tienen una función distinta en la gramática, por lo que participan también del proceso conocido como descategorialización, esto es, de la pérdida de algunas de sus propiedades morfosintácticas originales, en este caso, las de comenzar y empezar, puesto que en sus usos perifrásticos no funcionan como verbos transitivos, sino que van seguidos de una frase preposicional introducida por $a$, con un infinitivo como término, con la que forman una nueva unidad semántica.

(1) a. al situar y deslindar las distintas fincas, se comenzó a aludir a la séptima, pero no se escribieron sus linderos ni ubicación. (Anónimo, Colección documental del monasterio de santa María de las Dueñas, siglo XIII, GRADIA)

El uno de sus fijos luego le fue cobrir, el otro comenzó fuertemente a reír; cuando el padre lo vio, hóbole a maldezir. (Pedro López de Ayala, Libro de Palacio, siglo XIV, Gradia)

b. Empezó a escribir: present, tachado. Roto, con espacio para dos o tres palabras y lo mismo en el comienzo de la línea siguiente. (Anónimo, Colección diplomática del Monasterio de Carrizo, siglo XIII, GRADIA) los españoles los del pueblo sin esperar a cosa alguna empezaron a pelear con ellos y dende lo alto echar muchas piedras. (Hernán Cortés, Cartas de relación, siglo XVI, GRADIA)

Como veremos, este cambio implica la extensión o desplazamiento semántico y gramatical, porque los verbos originalmente transitivos amplían su valor semántico y pasan de referir 'el inicio de algo', que sintácticamente se analiza como el objeto directo, a expresar un sentido procedimental, es decir, se refieren a 'la manera o forma de ejecutar algo', en este caso, el aspecto del evento expresado por el verbo auxiliado en infinitivo, específicamente el punto inicial de ese evento o procedimiento.

Otros aspectos que pueden resultar interesantes sobre estas perífrasis son, por ejemplo, su origen y antecedentes latinos, que comentaremos más adelante, y responder a la pregunta de por qué ambas construcciones existen y conviven en nuestra lengua, si parecen expresar el "mismo significado", la incoatividad de la acción referida, especialmente considerando que los 
diccionarios definen comenzar y empezar de manera muy semejante ${ }^{4}$. De tal modo, la permanencia en nuestra lengua, así como su comportamiento diacrónico pueden suscitar dudas sobre cuál es la razón para conservar dos formas sinónimas o parcialmente sinónimas, pues su existencia puede entrar en conflicto con el criterio de economía en la lengua y con la afirmación de que dos formas distintas no expresan el mismo significado. Como veremos en este trabajo, el significado de las dos perífrasis es prácticamente el mismo; su alternancia, sin embargo, está relacionada con otros factores, como la tradición textual, y particularmente con el desarrollo de los verbos comenzar y empezar en sus usos plenos, diferencias pragmáticas que justifican la existencia de ambas porque se anclan a diferentes contextos y registros lingüísticos. De este modo, la alternancia de las dos perífrasis no tiene que ver específicamente con un cambio de significado.

Luego de observar el comportamiento diacrónico de las perífrasis que aquí estudiamos, además de lo anterior, queremos reflexionar sobre la periodización sintáctica de la lengua española en relación con una serie de cambios ocurridos alrededor del siglo XIX, entre ellos el incremento en el uso de algunas perífrasis verbales, que ha llevado a varios estudiosos a considerarlo como una etapa evolutiva clave para la diacronía y el cambio lingüístico. Aunque no es el objetivo central de este trabajo, llama nuestra atención el comportamiento diacrónico de comenzar a y empezar $a+$ INF alrededor de este periodo, en el que vemos un incremento de la perífrasis con empezar, poco después una nivelación en la frecuencia de uso de ambas formas y posteriormente el uso mayoritario de empezar $a$. Creemos que merece la pena relacionar estos fenómenos con la diversificación en el uso de otras perífrasis en nuestra lengua alrededor del periodo señalado. En Garachana (2017:19), por ejemplo, se establece la diacronía de las perífrasis modales en español. Los resultados al respecto muestran que hasta el siglo XIX eran dos las perífrasis más frecuentes, deber (de) + inf y haber de + inf y que la evolución de otras formas con valor modal tiene dos momentos cruciales, los siglos XV y XIX. A partir del XV, "se observa un ligero aumento del empleo de otras perífrasis, diferentes de deber (de)+ infinitivo y haber de + infinitivo, junto con el desplome de las construcciones con ser

4 Hemos consultado las definiciones de comenzar y empezar en los diferentes diccionarios académicos incluidos en el Nuevo tesoro lexicográfico de la lengua española de la Real Academia Española (http://buscon.rae.es/ntlle/SrvltGUILoginNtlle) sin encontrar gran diferencia. Llama la atención que en diferentes ocasiones se utiliza uno para definir el otro. 
(ser tenudo-tenido ø/a/de + infinitivo y ser de + infinitivo). A su vez, el siglo XIX muestra una aproximación significativa de la frecuencia de uso de las construcciones perifrásticas, de modo que las diferencias entre las perífrasis más usuales y las de empleo más marginal dejan de ser tan marcadas como lo habían sido en etapas anteriores" (Garachana 2017:19); veremos que ocurre algo similar en la diacronía de las formas que nos ocupan. Aunque no lo abordaremos aquí detalladamente porque creemos que es tema de un trabajo posterior, ocurre algo similar con otras perífrasis aspectuales, como lo muestran los resultados de Cuní ( $\rightarrow$ este volumen), de Garachana ( $\rightarrow$ este volumen) y de Hernández Díaz (en prensa).

El trabajo se estructura como sigue. Tras esta introducción, dedicamos el apartado §2 a la hipótesis. En la sección §3 describimos brevemente el corpus empleado. En $\S 4$ presentamos el análisis de las formas perifrásticas con ambos verbos, a partir de varios factores: en $\S 4.1$. el paralelismo entre los auxiliares y sus usos como verbos plenos; en $\S 4.2$. los infinitivos con los que se forman las perífrasis; en $\S 4.3$. la tradición textual en la que se documentan; en §4.4. el aspecto léxico de los verbos auxiliados; en §4.5. la persona gramatical de las perífrasis y en $\S 4.6$. el tiempo verbal de las formas. Posteriormente, en $\S 5$ hacemos una reflexión sobre el cambio en esta zona de la gramática en el siglo XIX y la periodización sintáctica de la lengua española. Finalmente, en $\S 6$ presentamos nuestras conclusiones.

\section{HIPÓTESIS}

Con base en la revisión histórica, el origen, el desarrollo y el comportamiento diacrónico y actual de las formas comenzar $a+\mathrm{INF}$ y empezar $a+\mathrm{INF}$ analizamos cuáles son sus valores semánticos y usos principales; si entran o entraron en competencia en algún momento e intentaremos responder por qué las dos se mantienen vivas. Discutiremos también si se pueden considerar construcciones sinónimas y en qué sentido e identificaremos los contextos a los que están ligadas, especialmente las tradiciones discursivas que las acogen. Para ello, acudimos a los planteamientos teóricos que ha hecho la gramaticalización.

La hipótesis que subyace a este trabajo es que, en nuestra lengua, el surgimiento y afianzamiento de la primera perífrasis documentada, comenzar $a+$ INF fue el antecedente formal y semántico para la formación de empezar $a+\mathrm{INF}$, bajo la premisa de que las relaciones que tienen las palabras a nivel 
léxico, en este caso los auxiliares, se extienden a otros contextos sintácticos. También, que la evolución de las dos perífrasis está íntimamente relacionada con el comportamiento que comenzar y empezar tienen como verbos plenos $\mathrm{y}$, por último, que el comportamiento diacrónico de ambas formas coincide con el de un conjunto de cambios más amplio en el ámbito de las perífrasis verbales, que sirve como argumento para plantear que el siglo XIX es un periodo importante en la evolución de nuestra lengua y que ello parece completar un panorama esbozado antes por otras propuestas de análisis diacrónico de la lengua española. Propondremos, pues, que el incremento en el uso de las perífrasis incoativas estudiadas se suma a otros cambios que parecen confirmar que el siglo XIX es un periodo clave para la historia del español.

\section{CORPUS}

Los datos estadísticos en los que se basan los resultados que presento han sido extraídos del corpus GRADIA (http://Gradiadiacronia.wixsite.com/Gradia/ corpus-Gradia). Corresponden al español en el periodo comprendido entre los siglos XI al XXI y están representadas diversas tradiciones discursivas: texto legal; notarial y administrativo; historiográfico; técnico; narrativo; ensayístico; epistolar; literatura sapiencial; discursos políticos; diálogos renacentistas; prensa escrita; textos orales y teatro. Para este trabajo hemos analizado un total de 3741 ocurrencias de las perífrasis comenzar a y empezar $a+\mathrm{INF}$, cuyas frecuencias totales aparecen en la Tabla 1. Recurrimos además al uso de algunos datos extraídos del Corpus diacrónico del español (CORDE) de la Real Academia Española; en cada ejemplo especificamos el corpus del que procede.

\begin{tabular}{|l|l|}
\hline comenzar $a+\mathrm{INF}$ & empezar $a+\mathrm{INF}$ \\
\hline $74 \%(2777 / 3741)$ & $26 \%(964 / 3741)$ \\
\hline
\end{tabular}

Tabla 1. Perífrasis totales documentadas

El primer hallazgo durante la conformación del corpus fue la disparidad en las frecuencias de uso de ambas construcciones y también que el mayor número de casos corresponde a la perífrasis comenzar a $+\mathrm{INF}$. En términos diacrónicos, documentamos el primer caso de comenzar a + INF en el siglo XI y el primero de empezar $a+$ INF en el XIII. Diacrónicamente, como 
se ve en la Tabla 2 (infra $\S 4$ ), de esta última no aparecen en el corpus registros correspondientes a los siglos XIV y XV; posteriormente se registra nuevamente en el siglo XVI, periodo en el que va aumentando su frecuencia hasta convertirse en la más usual de las dos formas en los cortes correspondientes a los siglos XIX y XX-XXI. En las páginas siguientes, trataremos de explicar este comportamiento diacrónico con base en el desarrollo de los verbos plenos con los que se forman estas perífrasis y también con base en los sentidos que expresan ${ }^{5}$.

\section{LAS PERÍFRASIS COMENZAR A Y EMPEZAR $A+\mathrm{INF}$}

A partir de los resultados que presentamos a continuación en la Tabla 2 se constata que, si bien el uso de comenzar $a+$ INF es cuantitativamente mayor que el de empezar a + INF en las frecuencias globales del corpus, al analizar las frecuencias relativas de uso de las dos perífrasis, su evolución diacrónica y sus ocurrencias por millón de palabras en cada siglo (véase infra Tabla 3 ), a partir del siglo XVIII se observa un cambio en cuanto a la distribución de las dos formas perifrásticas; a saber, empezar $a+$ INF se convierte en la forma más usual desde ese momento y hasta nuestros días.

5 Cabe mencionar que la diacronía de las dos perífrasis es similar a la que se presenta con otras construcciones perifrásticas que se desarrollan por pares, por ejemplo, lo que ocurre con deber y deber de + INF, sobre las que Rosemeyer (2017: 149-150) afirma que en el español antiguo no encuentra una diferencia respecto de la modalidad que expresan y que únicamente deber de + INF parece estar especializada en el énfasis textual. Advierte que en el español renacentista deber de + INF experimenta un fuerte incremento en la frecuencia de uso y es más proclive a expresar la modalidad epistémica que deber + INF, en parte, debido a la preferencia por utilizar la variante prepositiva en los textos de baja formalidad, ya que la modalidad epistémica es más probable en estos géneros textuales que en textos de un alto grado de formalidad, diferencia que luego se invierte, lo que lo lleva a formular la hipótesis de que aunque el uso de deber de + INF quedó marginado en textos de baja formalidad, en textos formales se conservó en función de la modalidad epistémica a causa de procesos de normativización. Los fenómenos señalados comparten con las perífrasis que estudiamos ahora el hecho de que la alternancia entre las dos formas no se da tanto a nivel de significado, sino a partir del registro lingüístico y la variación textual. Encontramos también cierta semejanza con lo que ocurre con las perífrasis causativas e incoativas con poner, estudiadas por Comer y Enghels (2017), desarrolladas a partir de la construcción locativa básica de poner. Aunque ambas construcciones se desarrollan de manera paralela, lo hacen a un ritmo diferente. 


\begin{tabular}{|c|c|c|}
\hline siglo & comenzar $a+\mathrm{INF}$ & empezar $a+\mathrm{INF}$ \\
\hline $\mathrm{XI}$ & $100 \%(1 / 1)$ & - \\
\hline $\mathrm{XIII}$ & $99 \%(509 / 510)$ & $>1 \%(1 / 510)$ \\
\hline $\mathrm{XIV}$ & $100 \%(221 / 221)$ & - \\
\hline $\mathrm{XV}$ & $100 \%(75 / 75)$ & - \\
\hline $\mathrm{XVI}$ & $98 \%(923 / 940)$ & $2 \%(17 / 940)$ \\
\hline $\mathrm{XVII}$ & $94 \%(682 / 723)$ & $6 \%(41 / 723)$ \\
\hline $\mathrm{XVIII}$ & $33 \%(35 / 107)$ & $67 \%(72 / 107)$ \\
\hline $\mathrm{XIX}$ & $48 \%(197 / 411)$ & $52 \%(214 / 411)$ \\
\hline $\mathrm{XX}-\mathrm{XXI}$ & $18 \%(134 / 753)$ & $82 \%(619 / 753)$ \\
\hline Total & $74 \%(2777 / 3741)$ & $26 \%(964 / 3741)$ \\
\hline
\end{tabular}

Tabla 2. Diacronía de las perífrasis estudiadas ${ }^{6}$

En la Tabla 2 se advierte también que la presencia de las dos perífrasis es relativamente baja en el periodo que va del siglo XI al XV; asimismo, que el siglo XVI es el momento de afianzamiento de comenzar a + INF. Según el avance diacrónico de ambas construcciones, la presencia de esta forma posibilita, a mi modo de ver, el avance de la perífrasis con empezar, pues se da solo cuando la perífrasis con comenzar se ha consolidado. En cuanto a este último verbo, documentamos pocos casos en la diacronía general; pero se advierte un incremento muy notable en el siglo XVIII y en los dos cortes posteriores, XIX y XX-XXI. A la luz de estas frecuencias absolutas, queremos destacar que, como ocurre con otras construcciones y particularmente con otras perífrasis, en el siglo XIX se dio un cambio en el par estudiado, que coincide con la reestructuración del paradigma perifrástico modal (cfr. Garachana 2017: 19), cambio en el cual es consistente la existencia de lazos semánticos y formales estrechos entre construcciones, que tienen un impacto en la gramaticalización y en la construcción de algunas formas.

Para ampliar los resultados de la Tabla 2, presentamos en la Tabla 3 los datos correspondientes al número de perífrasis documentadas en cada siglo por millón de palabras, con el fin de mostrar que comenzar $a+\mathrm{INF}$ es diacrónicamente más frecuente casi siempre, a excepción de los dos últimos

\footnotetext{
6 Decidimos juntar en un solo corte cronológico los datos de los siglos Xx y xxI debido al número de textos correspondientes al periodo actual, puesto que aún no representan ni la cuarta parte del siglo. La primra cifra en el paréntesis corresponde al número de ejemplos documentados de cada perífrasis en el periodo correspondiente y la segunda, después de la diagonal, al total que suman los casos de comenzar a y empezar a + INF en cada periodo.
} 
cortes cronológicos. Estos resultados son muy interesantes en cuanto al estudio y la interacción del léxico y de la gramática porque coinciden con el desarrollo de los verbos comenzar y empezar en sus usos como verbos plenos, como veremos.

\begin{tabular}{|c|c|c|}
\hline siglo & comenzar $a+\mathrm{INF}$ & empezar $a+\mathrm{INF}$ \\
\hline $\mathrm{XI}$ & $16(4)$ & 0 \\
\hline $\mathrm{XIII}$ & $185(509)$ & $0.3(1)$ \\
\hline $\mathrm{XIV}$ & $134(221)$ & 0 \\
\hline $\mathrm{XV}$ & $51(75)$ & 0 \\
\hline $\mathrm{XVI}$ & $256(923)$ & $5(17)$ \\
\hline $\mathrm{XVII}$ & $323(682)$ & $19(41)$ \\
\hline $\mathrm{XVIII}$ & $27(35)$ & $55(72)$ \\
\hline $\mathrm{XIX}$ & $103(197)$ & $112(214)$ \\
\hline $\mathrm{XX}-\mathrm{XXI}$ & $47(134)$ & $216(619)$ \\
\hline
\end{tabular}

Tabla 3. Frecuencia de las perífrasis por millón de palabras ${ }^{7}$

Creemos que la proporción de los resultados y la perspectiva que podemos tener de las perífrasis analizadas se aprecia mejor con base en la Tabla 3, pues queda claro que la perífrasis comenzar $a+\mathrm{INF}$ fue considerablemente más frecuente entre los siglos XI al XVII (2); que en el XVIII la frecuencia de uso de comenzar a y empezar $a+\mathrm{INF}$ es cuantitativamente similar, e incluso la segunda aventaja ligeramente a la primera en frecuencia, y que a partir del siglo XIX y en los dos más recientes, XX y XXI, los porcentajes de uso se invierten a favor de empezar a + INF como la más usual de las dos. De este modo, de las dos formas estudiadas, actualmente la perífrasis predominante es empezar $a+$ INF. También, podemos decir que el auge de las dos construcciones es tardío en la historia de la lengua española, específicamente el de empezar $a+\mathrm{INF}$, que inicia propiamente en el siglo XVIII (3a) y que la forma se consolida como más frecuente en el XIX (3b).

7 Las cifras que aparecen fuera del paréntesis corresponden a la frecuencia de las perífrasis por millón de palabras y las que aparecen dentro, a la frecuencia absoluta de casos fichados en cada periodo. 
(2) Comenzó a escribir $t u$, pero se percató de su error y modificó sobre la marcha. (Anónimo, Colección documental del Monasterio de Santa María de las Dueñas, siglo XIII, GRADIA)

El uno de sus fijos luego le fue cobrir,/ el otro comenzó fuertemente a reír;/ cuando el padre lo vio, hóbole a maldecir. (Pedro López de Ayala, Libro de Palacio, siglo XIV, GRADIA)

Ytem dixo quel prado de leyça que agora comencauan a cotar los de Arraualde que nunca lo viera cotar. (Anónimo, Colección documental del Monasterio de San Esteban de Nogales, siglo XV, Gradia)

(3) a. Ya más robusto y con disposición para sufrir los caminos y mesones de España, empecé a pagar a Dios los votos y los prometimientos con que procuré desde mi cama aplacar las suavidades de su justicia. (Diego de Torres Villarroel, Vida, ascendencia, nacimiento, crianza y aventuras del doctor Diego de Torres Villarroel, siglo XVIII, GRADIA) después que, obtenida mi libertad al punto mismo en que empezaba a peligrar la de mi patria, no sólo abracé con firmeza la santa causa de su defensa, sino que me negué a todas las sugestiones y ofertas lisonjeras. (Gaspar Melchor de Jovellanos, Memoria en que se rebaten las calumnias divulgadas contra los individuos de la Junta Central y se da razón de la conducta y opiniones del autor desde que recobró su libertad, siglo XVIII, GRADIA)

b. SIMÓN.- Cuando yo salía de la puerta, los vi a lo lejos, que iban ya de camino. Empecé a dar voces y hacer señas con el pañuelo. (Leandro Fernández de Moratín, El sí de las niñas, siglo XIX, GradiA)

Nunca había sido más feliz. ¿Quería satisfacer el amor propio a quien la edad empezaba a dar algunos disgustos? Pues Ana, la mujer más hermosa de Vetusta, le adoraba. (Leopoldo "Alas" Clarín, La Regenta, siglo XIX, GRADIA)

\subsection{Paralelismos entre los auXiliares y SU USO COMO VERBoS PlenOS}

Para entender el proceso que siguieron las dos perífrasis, creemos pertinente detenernos en la evolución de los auxiliares de ambas construcciones en sus usos como verbos plenos, pues siguiendo lo que se ha planteado antes (De Smet y Fischer 2017, Garachana y Rosemyer 2011, Garachana y Hernández Díaz, en prensa), creemos que la perífrasis empezar $a+\mathrm{INF}$ fue posible gracias a la existencia previa de comenzar $a+$ INF, pues la primera que se documenta, la de comenzar, sirvió como una construcción de soporte (originalmente en inglés supporting construction) para el surgimiento de la segunda, en el 
sentido de De Smet y Fischer (2017) ${ }^{8}$ : como una construcción que propició un proceso de creación analógica mediante el cual se creó una nueva forma, la perífrasis con empezar.

Así, la sinonimia entre empezar y comenzar a nivel léxico se extendió al ámbito sintáctico, como ocurre en la formación de otras construcciones en las que las relaciones semánticas entre las palabras motivan cambios gramaticales (vid. Garachana 2011, 2017; Garachana y Rosemeyer 2011; Garachana y Hernández Díaz, en prensa, Rosemeyer 2013). También creemos que la frecuencia de uso de ambos verbos como predicados plenos está vinculada con la frecuencia de uso de ambas formas. Con la intención de analizar la frecuencia de comenzar y empezar como verbos plenos y compararla con la diacronía de su empleo como auxiliares en términos cuantitativos, hemos contabilizado la aparición de ambos en sus usos plenos en el Corpus Diacrónico del Español (CORDE) de la RAE (www.rae. es), dado que, como es sabido, tiene un mayor número de datos. La Tabla 4 resume los resultados correspondientes a los mismos periodos del uso de los verbos como auxiliares en el corpus Gradia, con excepción del XI para el que no hay resultados.

\begin{tabular}{|c|c|c|}
\hline siglo & comenzar & empezar \\
\hline XIII & 5142 & 105 \\
\hline XIV & 4563 & 107 \\
\hline XV & 14265 & 366 \\
\hline XVI & 24498 & 1773 \\
\hline XVII & 12557 & 3428 \\
\hline XVIII & 1938 & 3914 \\
\hline XIX & 8328 & 11004 \\
\hline XX-XXI & 17543 & 16529 \\
\hline
\end{tabular}

Tabla 4. Frecuencia de uso de comenzar y empezar en el CORDE como verbos plenos

8 De acuerdo con estos autores, la existencia de una forma o construcción "facilitate the emergence of an innovative pattern, presumably because shared phonological, functional or syntactic components are already entrenched and give the 'innovative form' a selectional advantage". 
A partir de los datos presentados en la Tabla 4 creemos que, en efecto, se advierte un paralelismo entre comenzar y empezar en sus usos como verbos plenos y auxiliares. Es muy evidente y significativa la poca frecuencia de empezar en los primeros siglos, XIII al XV, e incluso en el XVI y el XVII, aunque en este último siglo ya aventaja a comenzar en frecuencia. Los resultados son aún más contundentes en el XIX y en el XX, en donde se advierte el incremento de empezar como verbo pleno. Así, creemos que el avance de la forma perifrástica con este predicado está vinculado al incremento en el uso como verbo pleno.

Como es sabido, hay una estrecha relación semántica entre los verbos comenzar y empezar. El primero tiene su origen en un verbo de movimiento y sus primeros usos estuvieron restringidos al ámbito de la liturgia. (Cum) ǐnǐtiāre se formó a partir del frecuentativo de un verbo de movimiento, ineō $>$ ǐnǐtīo, mediante el sufijo - it- que marca acción repetida. Así, ǐnĭtǐo significa originalmente 'ir a' en repetidas ocasiones o 'entrar en' continuamente, por lo que expresa el sentido de 'punto inicial de un estado que tiene una duración en el tiempo' y forma parte de los casos en los que un verbo de movimiento se gramaticaliza para expresar valores aspectuales (Segura Munguía 2006:s.v. iněo $)$. Dado que comenzar proviene de un verbo de movimiento (ěō, īre, īvì, ı̀tum, 'ir', 'andar', 'caminar', 'avanzar, 'trasladarse de un lugar a otro') metafóricamente significó "el inicio de algo", generalmente abstracto. Nos parece notable el que ĭnйtio fue originalmente una voz restringida a un ámbito especializado, la liturgia, de donde se extendió a la lengua general, en donde tuvo un valor específico y claramente marcado como un cambio de estado o condición en el iniciado en los misterios religiosos, pues en ese ámbito, quizá más que en otros, el pasar de una condición a otra implica una transformación significativa que se concibe como un cambio profundo en la espiritualidad, y fundamental, en la persona iniciada, puesto que ha comenzado un proceso que por lo general implica un conocimiento o un aprendizaje.

El verbo empezar, en cambio, se deriva del sustantivo pieza con el sentido primitivo de 'cortar un pedazo de alguna cosa y comenzar a usarla' (Corominas 1980:s.v. empezar). No obstante su origen diverso, ambos comparten el sentido inicial u original de un movimiento, que también en los dos verbos se da a nivel metafórico, pues tanto 'ir a' o 'entrar en' repetidas veces, como 'cortar un pedazo (de algo inmaterial o abstracto para empezarlo' implican un cambio de estado o movimiento, aunque se dé solo en el plano de la abstracción; así pues, los primeros registros para comenzar como verbo pleno tienen como objeto directo el inicio del discurso, de la historia, por ejemplo, o las primeras nociones (de algo). 
Fuero es que si por razon de muert o de enfermedat o de preson o por otra razon abondosa de embargo ante de la fin del pleito non podiesse seer hy el razonador que auia començado el pleito. (Anónimo, Fueros de Aragón, 1247, CORDE, s.v. començ*)

Semejava que era reína muy sabrosa,/ tenié en su cabeça corona muy fermosa/ luzié en derredor mucha piedra preçiosa,/ començó su razón a guisa de cabosa. (Anónimo, Libro de Alexandre, 1240-1250, CORDE, s.v. començ*)

Assi començo la auaricia de los iudios que nunqua se farta en requir que aquestos qui por lures cueytas reciben aueres dellos a priestamo. (Anónimo, Fueros de Aragón, 1247, CoRDE, s.v. començ*)

Et el Rico ome quando vió que engañar non lo podie comenzó la guerra con él aquella mas avibada que pudo. (Alfonso X, General estoria, 1248, CORDE, s.v. comenz*)

Asimismo, en los usos perifrásticos, se combina con mucha frecuencia con verbos de lengua como decir, hablar, contar, etc. y con otros que implican procesos mentales como pensar o escribir. Corominas (1980:s.v. comenzar) apunta también que comenzar es común a todos los romances de España y Francia, también al italiano, y que, en castellano, tuvo desde el principio concurrencia con empezar, la cual dio lugar al cruce compeçar registrada en el Cid.

El verbo empezar, derivado de pieza, tuvo el sentido de 'decentar (algo)', 'cortarlo en pedazos para comenzar a usarlo' (Corominas 1980:s.v. empezar) e, igualmente, se sitúa la primera documentación en el Cid. Tanto Corominas como el Diccionario de la lengua española (DLE) (RAE, en línea, actualización 2018) señalan no solo una estrecha relación semántica con decentar 'encentar', 'hacer que algo deje de estar sano o entero', sino incluso formal, pues encentar, originalmente encetar, tiene la segunda $\underline{n}$ epentética por analogía con comenzar. Aunque empezar ya se halla desde los textos más antiguos como mero sinónimo de comenzar, se nota la frecuencia de la construcción con régimen directo de cosa, ya sea concreta o abstracta (5), que es indudablemente etimológica $(* \operatorname{de}$ pieza $)$.

Tornemos a la 'storia e non la postpongamos; sigamos la carrera como la empezamos; adoremos la cruz e en Christo creamos, que la resurrección dignamente veamos. (Gonzalo de Berceo, Loores de Nuestra Señora, 1236-1246, CORDE, s.v. empez*)

La torr' de Babilón, los que la empeçaron,/ mal grado ayan ellos, ca no la acabaron;/ 
mancebos de mal seso, que con Dios se tomaron,/ cempellaron afirmes, nada non recabdaron. (Gonzalo de Berceo, El duelo de la Virgen, 1236-1246, CORDE, s.v. empez*)

Señores e amigos, Dios sea end laudado,/ el segundo libriello avemos acabado,/ Queremos empeçar otro a nuestro grado,/ que sean tres los libros e uno el dictado. (Gonzalo de Berceo, Vida de Santo Domingo de Silos, c. 1236, CoRDE, s.v. empez*)

En algunos casos, aunque el objeto directo del verbo es una entidad abstracta, se transparenta la idea de iniciar algo que tiene partes o está dividido en ellas, aunque tanto las partes como las entidades sean de tipo abstracto. Así, empezar tiene un uso metafórico o figurado, como en (6), donde el propio sustantivo partidas, derivado de partir, se refiere a las parcialidades en que se divide un todo, que no es precisamente concreto.

el Rey don ferrando su padre auja començado a fazer los libros delas partidas este Rey don alfonso su fijo fizo las acabar. El Rey Don fernando empezo las partidas i Don alfonso Las acabo. (Anónimo, Crónica de Alfonso X, 1340-1350, CORDE, s.v. empez*)

A nuestro modo de ver, los contextos puente para la conformación de las perífrasis con ambos verbos -es decir con dos posibles interpretaciones-son casos como los de (7). En estos ejemplos, el infinitivo no aparece pegado al auxiliar y tiene aún régimen de algo que se asemeja en función sintáctica a un objeto directo. Son contextos puente porque el infinitivo expresa una noción semejante a una característica o un estado transitorio de la entidad pospuesta al verbo y al mismo tiempo también comenzar... a herir y empezar ... a rodear pueden interpretarse como perífrasis verbales.

(7) a. Fueron a sus posadas, echaron s'a dormir;/ començaron las alas los gallos a feryr; / levantáronse todos, misa fueron oýr,/ confessarse a Dios, pecados descubrir. (Anónimo, Poema de Fernán González, c. 1250, CORDE, s.v. començ*)

b. Mandó todas las gentes en un campo fincar,/ empeçólas él mismo por sí a rodear;/ mandólas seer quedas, la çaga esperar,/ ca avién un portiello traviesso a passar. (Anónimo, Libro de Alexandre, 12401250, CORDE, s.v. empeç*)

Con respecto de comenzar, Corominas añade que fue muy clásico y que hoy pertenece al lenguaje literario y de tono elevado y que, en la actualidad, se emplean además como sinónimos principiar e iniciar. A propósito de esta última aseveración de Corominas, queremos destacar que creemos que el notable descenso en las frecuencias de comenzar $a+\mathrm{INF}$ en épocas recientes 
está relacionado con el uso actual del verbo pleno, caracterizado como propio del lenguaje literario y de tono elevado y que ello bien pudo ser un detonante más para la consolidación de empezar $a+$ INF y para el repliegue de comenzar a + INF a contextos discursivos muy específicos, a la luz de lo planteado por Rosemeyer (2015) sobre la persistencia de las "construcciones moribundas" en los textos más conservadores. Creemos que los datos de la Tabla 4 que presentamos corroboran este comportamiento diacrónico que se observa tanto en los usos plenos como en los usos auxiliares.

\subsection{LOS INFINITIVOS DE LAS PERÍFRASIS}

En cuanto a los infinitivos con los que se forman las perífrasis, la nómina es bastante amplia y se diversifica enormemente en las etapas más recientes, específicamente después del siglo XVIII y especialmente en el XIX y en el XX con el verbo empezar como auxiliar. En cambio, con comenzar, si bien desde el principio el tipo y el número de predicados en infinitivo es muy variado, diacrónicamente se advierte la especialización o reducción semántica de los mismos hacia ámbitos formales o de carácter técnico, como explicaremos ahora.

Con el verbo comenzar como auxiliar, el primer infinitivo documentado en el corpus coincide con el que aparece con empezar; con ambas perífrasis es escribir. En el siglo XVIII, los infinitivos se refieren a acciones y algunos son de tipo estativo, como haber y tener o de cambio de estado como crecer. En el XIV no se nota ningún cambio significativo, excepto que se incrementan los casos en los que hacer aparece seguido de un nominal, casos en los que este verbo bien podría ser sustituido por un verbo pleno que integrara semánticamente a ambos, nos referimos a casos como comenzar a hacer guerra (equivalente a guerrear, pelear, combatir), comenzar a hacer leyes (equivalente a legislar). Entre los siglos XV y XVII, no parece haber gran cambio semántico en los predicados en infinitivo. No es sino hasta el XVIII cuando se observa una disminución cuantitativa importante de esta perífrasis, acompañada de la especialización de los infinitivos, por ejemplo, lograr, razonar, predicar, ponderar, más evidente todavía en el XIX, olfatear, vislumbrar, interpretar (las Escrituras), extirpar, exhumar, redactar, entibiar, fermentar, difundir, influir, moralizar. La tendencia se mantiene en los dos siglos siguientes, donde los infinitivos son verbos de uso restringido o acotado a cierto tipo de discurso y de registro lingüístico, por ejemplo, analizar, erosionar, menguar, minar, cortejar, quebrantar, discrepar, entre algunos otros. 
Con empezar como auxiliar, aparecen primero predicados referidos a acciones o actividades. En el siglo XIII, por ejemplo, el único infinitivo en el corpus es escribir; la variedad de los predicados se incrementa conforme pasa el tiempo. En el XVI, además de los verbos que denotan acciones, aparecen otros con características semánticas distintas, como vivir. En el XVII, se combina con repasar, conocer, deducir, experimentar y tener, que no se refieren a acciones, entre otros muchos que sí lo hacen. En el XVIII, aparecen padecer, enloquecer, temer, gozar o restablecer, entre otros, que se caracterizan por tener sujetos no agentivos; si bien se espera que restablecer vaya con entidades agentivas animadas, el ejemplo no corresponde a ese esquema sintáctico (8).

Carlos disipa, destruye, aniquila de un golpe estos partidos, y dando entrada en nuestras aulas a la libertad de filosofar, atrae a ellas un tesoro de conocimientos filosóficos que circulan ya en los ánimos de nuestra juventud y empiezan a restablecer el imperio de la razón. (Gaspar Melchor de Jovellanos, Elogio de Carlos III, siglo XVIII, Gradia)

Para el XIX, aparecen por primera vez predicados referidos a fenómenos atmosféricos, anochecer, clarear y otros que no llevan sujetos agentes, como brillar, notar, ser, estar, olvidar, pasar, prevalecer y entrever. En los dos siglos más recientes, XX y XXI, se registran encontrar, notar, contemplar, sentir, sospechar, existir, envidiar. Así pues, el avance y la diversificación diacrónica de los infinitivos en las perífrasis corroboran que para el siglo XVIII la perífrasis estaba consolida en términos semánticos, pues aparecen verbos referidos a estados en los que el valor aportado por empezar es más abstracto. La gramaticalización parece más contundente en el XIX, en donde aparecen verbos referidos a fenómenos atmosféricos y otros de tipo estativo.

$\mathrm{El}$ análisis de la trayectoria individual de las perífrasis comenzar a y empezar $a+$ INF nos lleva a plantear algunas conclusiones relacionadas con el comportamiento diacrónico general de las perífrasis modales al que nos hemos referido en el aparatado anterior. Como afirma Garachana (2017:21), la historia de las perífrasis modales muestra un entramado de relaciones que llevan a concluir que la evolución de estas formas exige examinar paralelamente el proceso evolutivo de construcciones (cuasi) sinónimas, puesto que conforman un paradigma dentro del cual las presiones analógicas son determinantes. Esto ocurre también en las perífrasis incoativas estudiadas, pues existen estrechos lazos sintácticos y semánticos entre ellas. No estamos ante un proceso de sustitución, al menos concluido, en el que una forma innovadora, empezar a $\mathrm{INF}$, haya desplazado a otra, comenzar $a+\mathrm{INF}$, sino ante dos construcciones sinónimas que forman un par en el que 
la presión analógica fue determinante para que empezar $a+$ INF se formara y se afianzara en la lengua, con base en sus similitudes léxicas ya señaladas.

\subsection{LA TRADICIÓN TEXTUAL}

En cuanto a la tradición textual se refiere, la diferencia central en el uso y la alternancia de ambas formas está en géneros textuales específicos: la historia $\mathrm{y}$, en menor medida, en la narrativa, la oralidad y la literatura sapiencial, como puede observarse en la Tabla 5.

\begin{tabular}{|l|c|c|}
\hline & comenzar a + INF & empezar a + INF \\
\hline historia & 2020 & 131 \\
\hline narrativa & 277 & 453 \\
\hline epístola & 145 & 24 \\
\hline sapiencial & 116 & 0 \\
\hline ensayo & 48 & 47 \\
\hline legal & 45 & 3 \\
\hline diálogo & 34 & 3 \\
\hline oral & 28 & 229 \\
\hline técnico & 27 & 23 \\
\hline notarial & 12 & 1 \\
\hline prensa & 12 & 14 \\
\hline discurso & 7 & 19 \\
\hline teatro & 5 & 17 \\
\hline poesía & 1 & 0 \\
\hline
\end{tabular}

Tabla 5. Tradición textual en que aparecen las perífrasis estudiadas

Aunque es evidente que los géneros textuales considerados en el corpus GRADIA son diversos y que el auge de algunos de ellos está ligado a periodos determinados, comenzar $a+$ INF se documenta con más frecuencia en textos asociados al registro lingüístico culto: la historia, la epístola, los documentos legales y la literatura sapiencial (9). En cambio, empezar $a+$ INF predomina en la narrativa y la lengua oral (10); de modo que los resultados del análisis 
del corpus coinciden con la apreciación hecha por Corominas, a la que nos hemos referido en este mismo apartado, respecto de que comenzar "fue muy clásico y que hoy pertenece al lenguaje literario y de tono elevado". El uso del verbo pleno ligado a esos contextos, a mi modo de ver, ha sido fundamental para la preferencia y la extensión de empezar en las perífrasis incoativas.

el poder del condestable le tuvieron más opreso que cuando comenzó a reinar. (Jerónimo Zurita, Anales de Aragón, siglo XVI, GrADIA) en nombre de Vuestra Majestad fundé allí una villa que por ser el día en que se comenzó a talar el asiento de la Natividad de Nuestra Señora le puse a la villa aquel nombre. (Hernán Cortés, Cartas de relación, siglo XVI, GRADIA)

A esto se vos rresponde que nos plaçe de ello, e nos esforzarémos a lo facer, especialmente por que vosotros nos lo suplicais en nonbre del Reyno, e ansy lo avemos ya comenzado a hablar con vosotros e con otros destos nuestros Reynos. (Anónimo, Ordenamiento de las Cortes de Valladolid de 1518, siglo XVI, GradiA)

(10) Empecé a dar voces y hacer señas con el pañuelo; se detuvieron, y apenas llegué y le dije al señorito lo que usted mandaba, volvió las riendas. (Leandro Fernández de Moratín, El sí de las niñas, siglo XIX, Gradia)

Empecé a caminar, a caminar... Barcelona se había quedado infinitamente vacía. El calor de julio era espantoso. Atravesé los alrededores del cerrado y solitario mercado del Borne. (Carmen Laforet, Nada, siglo XX, GRADIA)

hacia un perfeccionamiento en técnicas quirúrgicas, empecé a ver escuelas de sordos, empecé a hablar con la gente en relación con este tipo de problemas, y así como, poco a poco y-digamos-del cuarenta y seis al cincuenta y uno, inicié una nueva etapa de autoformación. (Juan M. Lope Blanch, El habla de la ciudad de México, siglo XX, GRADIA)

Estamos ante un cambio gramatical que gira en torno a las palabras y a las construcciones en que aparece, que no puede ser explicado meramente por la ampliación de las redes semánticas de las voces, sino como el resultado de cambios analógicos que se activan a partir de la sinonimia y la polisemia generada a lo largo de la historia del significado de las palabras (cfr. Garachana 2011). De tal manera, estos resultados, a mi modo de ver, contribuyen a entender con mayor detalle el comportamiento general de las perífrasis verbales y también ofrecen resultados relativos a la conformación de la gramática pues, aunque no se trata de procesos de gramaticalización 
que satisfagan todos los requisitos para hablar de un cambio cumplido o que reúnan las cualidades aducidas para las formas gramaticalizadas, pueden explicarse como procesos de copias léxicas propiciadas por analogías que ocurren entre palabras y que se extienden a la gramática. La comparación de frecuencias pone de relieve que la expansión de unas construcciones suele ser crucial para el desarrollo de otras. Así también, la diversificación de formas perifrásticas se incrementa, por lo que las perífrasis que presentan algunas restricciones de uso se documentan cada vez con menor frecuencia a favor de otras mejor integradas en el sistema perifrástico.

\subsection{El ASPECTO LÉXICO DEL VERBO EN INFINITIVO}

Otro argumento de que estamos ante el avance de una forma sinónima a partir de otra es la muy similar combinación de las dos perífrasis con infinitivos semejantes en cuanto al aspecto léxico se refiere.

\begin{tabular}{|l|c|c|}
\hline & comenzar $a+\mathrm{INF}$ & empezar $a+\mathrm{INF}$ \\
\hline actividad & 461 & 236 \\
\hline realización & 1841 & 345 \\
\hline logro & 17 & 3 \\
\hline estado & 458 & 380 \\
\hline
\end{tabular}

Tabla 6. Aspecto léxico del verbo en infinitivo

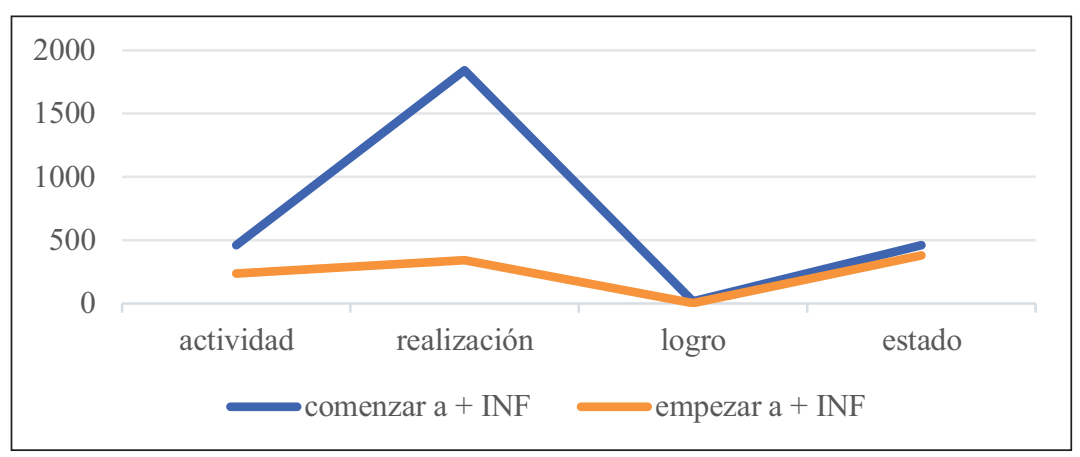

Gráfico 1. Aspecto léxico del verbo infinitivo 
Los resultados que presentamos en la Tabla 6 y que esquematizamos en el gráfico 1 permiten observar que el comportamiento de las perífrasis es similar en cuanto al aspecto verbal del infinitivo con el que se combinan. Los de mayor frecuencia son los eventos en los que se puede marcar o destacar el inicio, es decir, las actividades y las realizaciones, en contraste con el bajo control de la acción que se tiene en los logros y los estados. Consideramos que estos resultados apoyan la idea de que una perífrasis es una copia léxica de la otra, dada la similitud de los sentidos que expresan y los predicados con los que se combinan. Entendemos copia léxica como un cambio gramatical que no ocurre a partir de un cambio conceptual vinculado con procesos congintivos como la metáfora y la metonima como en los procesos de gramaticalización, sino que progresa como un cambio por sustitución léxica que trasciende al ámbito gramatical (cfr. Garachana y Rosemeyer 2011: 36-38). En este caso, la perífrasis con empezar se forma y se consolida con base en la sinonimia y la interacción que este predicado tiene con comenzar como verbos plenos. En el proceso destaca, pues, la sinonimia entre los auxiliares comenzar y empezar que, como dijimos antes, no pierden nunca su significado léxico, aunque sí modifican su estructura argumental y sintáctica. La existencia y supervivencia de ambas perífrasis se relaciona con la diversificación de las formas perifrásticas que pueden expresar incoatividad y suponen, en ese sentido, un proceso de gramaticalización porque se amplía un mecanismo de generación de gramática.

\subsection{LA PERSONA GRAMATICAL EN LAS PERÍFRASIS}

Cabe añadir que lo mismo ocurre en cuanto a la persona gramatical de las perífrasis que nos ocupan. Los resultados son similares cuando se compara el uso de las dos estructuras. Como es previsible, el empleo se concentra en las terceras personas, tanto del singular como del plural con las dos perífrasis, aunque empezar es ligeramente más flexible para usarse con las primeras personas también. A pesar de ello, la imagen de la línea que dibujan ambas es muy semejante. De ahí la propuesta de análisis de que se trata de una sinonimia de tipo estructural, por llamarlo de alguna forma. 


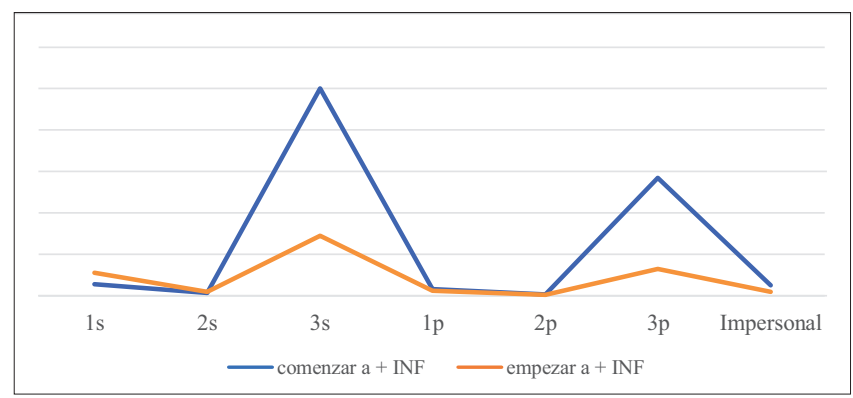

Gráfico 2. Persona gramatical

\subsection{LOS TIEMPOS VERBALES}

Por último, hemos analizado los tiempos verbales en los que se registran las dos construcciones. Los resultados del gráfico 3 se explican a partir de la semántica de las propias perífrasis, pues los pretéritos, tanto el perfecto como el imperfecto, van bien con el valor aspectual expresado por la incoatividad. Las perífrasis focalizan un momento al inicio de la acción concluida o no en el pasado. Por el contrario, el aspecto verbal que añaden las perífrasis no es compatible con la expresión del futuro. El comportamiento de las dos perífrasis es muy similar en cuanto al tiempo verbal en que aparecen, lo que apoya la idea de que con ambas se expresan valores semánticos similares.

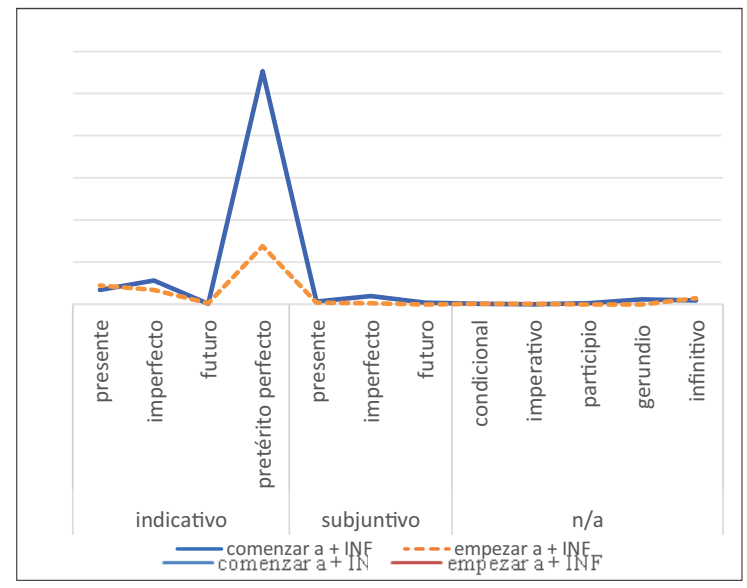

Gráfico 3. Tiempos verbales 
En síntesis, la alternancia de comenzar a y empezar $a+$ INF no parece darse en función de que cada una exprese contenidos semánticos distintos, sino que los valores que expresan son muy semejantes y el avance de la segunda se dio a partir de la primera. Lo que sí observamos es que cada una está ligada a contextos y registros específicos y, al parecer, también con un periodo, según vimos para los dos últimos siglos.

Si tuviéramos que analizar estos resultados a luz de la teoría de la gramaticaliazación, resultaría difícil explicar la permanencia de comenzar $a+\mathrm{INF}$, considerando que la gramaticalización consiste en la fijación de estrategias discursivas, de manera que los fenómenos lingüísticos que, en un estado de lengua dado, operan en un nivel discursivo textual, en un nivel más pragmático se convierten con el paso del tiempo en construcciones gramaticales convencionales, carentes ya de condicionamientos pragmáticos (Traugott 1982, 1989, 2003). Sería difícil por varios motivos, entre ellos porque al parecer en este momento el uso de las formas estudiadas sigue estando ligado a los contextos en los que se usa. También porque una forma no ha suplantado a la otra, sino que operan como construcciones sinónimas y complementarias, puesto que las dos perífrasis están convencionalizadas y tampoco parecen haberse (re)cargado con nuevos significados a través del uso en contextos específicos. Como ya apuntamos antes, el empleo de ninguno de los dos auxiliares ha involucrado el vaciamiento semántico completo de sus usos como verbos plenos, pero sí se han extendido y generalizado a nuevos contextos y han modificado sus propiedades morfosintácticas originales. Se trata de un proceso gradual, porque el comportamiento de las perífrasis ha sido muy estable durante una diacronía amplia, pero sí vemos en un punto un cambio en cuanto a las frecuencias de uso y los contextos en los que aparecen. Estamos, creo, ante un cambio en proceso que se caracteriza por la ampliación y generalización de una de las formas, pero que no implica la desaparición de la otra. Por eso, a mi modo de ver, resulta más claro explicar su comportamiento a la luz de la gramática de construcciones, en la que una forma funciona como "una fuerza centrípeta que atrae a otras o que fomenta la creación de nuevas estructuras que imitan el modelo de la primera" (Garachana y Hernández, en prensa) en la que la primera funciona como 'construcción de soporte' (De Smet y Fischer 2017).

Como último apartado de este trabajo, hablaremos ahora sobre si los datos presentados pueden ser considerados como una contribución para abonar a la periodización sintáctica de la lengua española. 


\section{EL SIGLO XIX Y LA PERIODIZACIÓN SINTÁCTICA DE LA LENGUA ESPAÑOLA}

Queremos ahora vincular estos resultados con varias ideas que se han planteado a propósito de la relevancia del siglo XIX para la historia del español (Company 2017, Garachana 2017, Melis, Flores y Bogard 2003). Company (2017: 93) afirma que el XIX "se muestra como un siglo cuya caracterización básica es de fuertes incrementos y generalizaciones de fenómenos de la sintaxis nuclear del español, que viene manifestándose desde siglos antes", lo que puede llevarnos a plantear si se puede considerar un periodo para la diacronía del español.

De acuerdo con el conjunto de hallazgos presentados en Garachana (2017), la evolución de las perífrasis verbales modales en español tiene dos momentos cruciales, los siglos XV y XIX. En el primero se advierte:

un incremento en el uso de algunas formas que se registraban antes, pero con una baja frecuencia, y al mismo tiempo el desplome de otras; en el segundo, se da una nivelación o redistribución en cuanto a las frecuencias de las perífrasis modales, pues las diferencias porcentuales entre las formas más usuales y las de empleo marginal dejan de ser tan marcadas como lo habían sido en etapas anteriores (Garachana 2017: 19).

A esta serie de cambios puede sumarse la evolución diacrónica de las perífrasis comenzar a y empezar $a+\mathrm{INF}$, en las que igualmente se da una redistribución en cuanto a sus frecuencias de uso y en cuanto a su alternancia. Si bien el porcentaje de uso de ambas es muy similar alrededor del siglo XIX, antes se dio una nivelación a favor de empezar a que en el XVII era muy poco frecuente; y ya para los siglos XX y XXI estamos ante una redistribución, puesto que dicha perífrasis que había sido poco usual se convierte en la más frecuente. Y no solo eso, sino que se multiplica su frecuencia con respecto de las etapas anteriores. De manera que, lo que hemos encontrado sobre las perífrasis aspectuales incoativas analizadas se corresponde de manera muy directa con lo ocurrido en la reestructuración del sistema perifrástico modal del español.

Frente a lo anterior, creemos que hay evidencias importantes que constatan que el siglo XIX es un punto importante en la diversificación, el incremento, la gramaticalización y la consolidación de las perífrasis verbales, no solo en el ámbito de la modalidad, sino también en el de la aspectualidad. Nuestros resultados sobre las perífrasis incoativas estudiadas corroboran y reafirman la idea de que el XIX es un periodo de esenciales continuidades a lo largo de la diacronía sintáctica del español, planteada en Company (2017: 
91-95) con base en el análisis de veinticinco cambios en áreas categoriales diversas y fenómenos sintácticos distintos, en los que el comportamiento común que se advierte son fuertes incrementos y generalizaciones de fenómenos nucleares en la sintaxis del español; también se suma a lo que Garachana (2017) señala con respecto de las perífrasis modales.

A partir de diversos fenómenos ocurridos en el siglo XIX, se ha planteado la existencia de un tercer periodo evolutivo en nuestra lengua (Melis, Flores y Bogard 2003), pues, aunque los manuales y tratados de historia del español establecen dos grandes etapas en su evolución, una a principios del siglo XV y otra entre los siglos XVI y XVII, la supuesta estabilidad del sistema del español no parece serlo si se considera que muchos cambios siguen ocurriendo entre los siglos XVIII y XIX, e incluso aún en nuestros días. De manera que Melis, Flores y Borgard (2003: 2) hablan de este último periodo como otra fecha divisoria de probable relevancia para dar cuenta de la historia del español. También han dicho que la etapa que se inicia con el siglo XIX, a la que denominan periodo moderno, se encuentra todavía abierta a principios del siglo XXI.

Queremos retomar esta última idea pues, el comportamiento de las perífrasis incoativas aquí estudiadas se corresponde con lo que señalan Melis, Flores y Bogard, pues su alternancia sigue presente hasta nuestros días y no sabemos si en algún momento una de las dos construcciones dejará de emplearse a favor de la otra, aunque parece que hay una fuerte tendencia a que así sea. A la luz del comportamiento de las formas perifrásticas analizadas, también queremos reflexionar sobre algunas ideas planteadas por Company (2017) sobre los estudios lingüísticos sobre el siglo XIX. Primero, que gracias a que este periodo cada vez está mejor representado en los trabajos sobre sintaxis histórica con base en la lingüística de corpus, se puede constatar que, en efecto, en este siglo ocurren múltiples cambios en $s^{9}$ y también cambios continuos en muy diversas zonas categoriales del español, en los que hay

9 Company (2017: 88-89) llama cambio en $s$ al más común en la diacronía y en la sociolingüística sincrónica, único tipo de cambio considerado como válido para las teorías de difusión del cambio por ser producto de la dinámica interna en la lengua. También porque, siguiendo los criterios de la lingüística variacionista, muestran el origen, la difusión y la generalización de un fenómeno, dado que la construcción se integra por completo a la gramática, luego se vuelve más frecuente y se diversifica formalmente. El comportamiento diacrónico de la perífrasis empezar $a+$ INF se ajusta a lo que se ha dicho sobre los cambios en $s$; una forma tiene de relativa a poca frecuencia de uso durante un periodo amplio $\mathrm{y}$, en un momento determinado, su empleo se incrementa considerablemente, de modo que sus frecuencias dibujan una forma similar a una $s$ al graficarlos estadísticamente. 
una pauta de comportamiento diacrónico común: es un siglo caracterizado por fuertes incrementos y generalizaciones de fenómenos.

Ante estos hechos, Company (2017: 93) afirma no saber a ciencia cierta si el siglo XIX constituye un periodo por sí mismo por los problemas teóricos y metodológicos que implica el propio concepto de periodización. Como plantea la autora, este concepto dista de ser monosémico, puesto que puede entenderse como un 'todo' con límites de 'inicio' y 'final', lo cual es difícil de establecer y clarificar referido a la lengua, pues como sabemos, por el contrario, su esencia es la continuidad. También porque metodológicamente se han equiparado los periodos de estudio con los siglos cronológicos de manera arbitraria y convencional porque resulta fácil hacerlo en función de la datación de las obras consideradas en los corpus diacrónicos, de modo que los resultados a este respecto pueden ser discutibles. Otros autores, como también señala Company (2017: 82) (cfr. también Melis y Flores 2015: 9), han intentado definiciones operativas para la periodización que proponen que los periodos son "porciones de tiempo más o menos extensas durante las cuales, pese a los cambios que no dejan de producirse en el uso de la lengua, se mantiene un mismo conjunto básico de patrones lingüísticos o un mismo sistema estructural" (Company 2017: 82). Estamos de acuerdo con Company en que, con todo, establecer periodos no es un asunto fácil en relación con el cambio lingüístico y la estabilidad en el cambio. Tampoco es tarea simple definir, como ella misma señala, por ejemplo, cuántas estructuras, cuántos quiebres diacrónicos hay que considerar, ni tampoco si todos los tipos de cambios sintácticos tienen el mismo peso en la caracterización de un periodo. A la luz de muchos fenómenos de cambio, el XIX resulta un siglo continuo solo al integrarlo en diacronías amplias, como hicimos en este trabajo.

A las dificultades planteadas en este último apartado hay que sumar la cercanía en el tiempo que aún suponen para nosotros los siglos XIX y XX y el hecho de que algunos de los cambios iniciados en esos periodos se pueden caracterizar por ser cambios en proceso con respecto de los cuales habrá que esperar el desenlace o cauce final, por lo que, aparentemente, la distancia temporal es clave para entender la diacronía y para establecer periodizaciones con respecto de la historia de la lengua. Pese a lo anterior, me parece que es innegable que el siglo XIX es un punto clave en la diacronía del español y que lo es desde la gramática histórica interna y no solo por factores de tipo externo, como algunas veces se ha aducido (cfr. Company 2017: 78). Los fenómenos aquí presentados se suman a los estudios que van en este sentido. 


\section{CONCLUSIONES}

He presentado la evolución diacrónica de las perífrasis comenzar a y empezar $a+$ INF con el objetivo de ahondar en la importancia que tiene la sinonimia entre las palabras como motivación de ciertos cambios gramaticales para contribuir a los estudios enfocados en la influencia que una o algunas de las acepciones de una palabra puede tener en construcciones donde esta interviene, a tal punto que, a partir de una construcción, se pueden generar construcciones nuevas que han sido llamadas "copias léxicas".

En esa misma dirección, he presentado algunos factores relacionados con el significado y la conformación sintáctica de las perífrasis analizadas, que muestran que los cambios que afectan una palabra no pueden ser explicados simplemente por la ampliación de su red semántica, sino que interviene una rica y compleja relación de sinonimias y polisemias generadas a lo largo de la historia del significado de las palabras. También, que una construcción gramatical bien asentada en la lengua contribuye al desarrollo de otras y que ello forma parte de los procesos de gramaticalización y cambio lingüístico, dado que no es necesario que una construcción suplante a otra en los procesos de cambio, ni tampoco que las formas implicadas en la formación de una construcción se vacíen por completo de sus sentidos léxicos originales, como ocurre con los auxiliares comenzar y empezar en las perífrasis estudiadas. Además, he mostrado que la conservación y la alternancia de ambas perífrasis se relaciona con los usos como verbos plenos de ambos auxiliares, restringidos por el contexto y el registro lingüístico en que se usan, lo cual está relacionado con el concepto de copia léxica, pero también con el hecho de que las construcciones moribundas o que presentan mayores restricciones de uso que otras, se conservan o perviven en registros lingüísticos específicos. La interacción entre contexto, registro y elección de las formas propias de ciertos géneros o discursos explica la pervivencia de dos perífrasis prácticamente sinónimas pero en distribución complementaria, por llamarle de alguna manera.

Por último, hemos presentado evidencia sobre la importancia del siglo XIX en la periodización de la sintaxis histórica de la lengua española y hemos intentado contribuir a la idea de que, en la presentación de diacronías amplias como la que hicimos en este trabajo, este periodo es clave, puesto que en él se amplían y se diversifican muchas formas atestiguadas en periodos anteriores. Ante la interrogante planteada sobre qué constituye un periodo desde una perspectiva teórica en los estudios sobre cambio lingüístico, coincidimos con reflexiones previas en la apreciación de que es difícil establecer criterios claros al respecto, pero también pensamos, como otros autores, que hablar 
de periodización es indispensable para entender las continuidades y las discontinuidades que ocurren en la lengua. Creemos que las reflexiones sobre la relevancia del siglo XIX, en donde parecen consolidarse algunos fenómenos sintácticos, tendrán respuesta una vez que tengamos mayor distancia temporal con respecto de ese siglo.

\section{REFERENCIAS BIBLIOGRÁFICAS}

OBRAS DEL CORPUS CITADAS (EN ORDEN CRONOLÓGICO) ${ }^{10}$

(Siglo XIII) Fernández Flórez, José Antonio y Marta Herrero de la Fuente. 1999-2005. Colección documental del monasterio de Santa María de las Dueñas. León: Centro de Estudios e Investigación San Isidoro/ Caja España de Inversiones.

(Siglo XIII) CASAdo Lobato, María Concepción. 1983. Colección diplomática del Monasterio de Carrizo. León: Centro de Estudios e Investigación San Isidoro/ CSIC/ Caja de Ahorros y Monte de Piedad.

(Siglo XIV) López de Ayala, Pedro. 1978. Libro de Palacio, edición de Libro rimado de Palacio, Jacques Joset (ed.). Madrid: Alhambra.

(Siglo XV) Cavero Domínguez, Gregoria. Colección documental del Monasterio de San Esteban de Nogales. León: Caja España de Inversiones/ Archivo Histórico Diocesano de León.

(Siglo XVI) Cortés, Hernán. 2004. Cartas de relación. México: Porrúa.

(Siglo XVI) Zurita, Jerónimo. Anales de Aragón. Edición electrónica de José Javier Iso (coord.), María Isabel Yagüe y Pilar Rivero. Publicación número 2.473 de la Institución "Fernando el Católico" (Excma. Diputación de Zaragoza).

(Siglo XVI) Anónimo. 1861-1903. Ordenamiento de las Cortes de Valladolid de 1518. Edición digital Cervantes Virtual basada en la de Madrid: Imprenta y Estereotipia de M. Rivadeneira.

(Siglo XVIII) Torres Villarroel, Diego de. 1799. Vida, ascendencia, nacimiento, crianza y aventuras del doctor Diego de Torres Villarroel. Edición digital Cervantes Virtual basada en la de Madrid: Imprenta de la Viuda de Ibarra. Cotejada con las ediciones críticas de Guy Mercadier (Madrid, Castalia, 1972), Dámaso Chicharro (Madrid, Cátedra, 1984), Russell P. Sebold (Madrid, Taurus, 1985) y Manuel María Pérez López (Madrid, Espasa Calpe, 1989).

(Siglo XVIII) Jovellanos, Melchor Gaspar De. 1811. D. Gaspar de Jovellanos a sus compatriotas: Memoria en que se rebaten las calumnias divulgadas contra los individuos de la Junta Central y se da razón de la conducta y opiniones del autor desde que recobró su libertad. Edición digital Cervantes Virtual basada en la de Coruña: Oficina de Francisco Cándido Pérez Prieto.

10 La lista completa de las obras que forman el corpus Gradia puede consultarse en $<$ https://Gradiadiacronia.wixsite.com/Gradia/corpus-Gradia $>$. 
(Siglo XVIII) Jovellanos, Melchor Gaspar de. 1788. Elogio de Carlos III, leído en la Real Sociedad Económica de Madrid el día 8 de noviembre de 1788. Edición de Vicente Llombart i Rosa y Joaquín Ocampo Suárez-Valdés. Alicante: Biblioteca Virtual Miguel de Cervantes, 2010.

(Siglo XIX) Fernández de Moratín, Leandro. 1806. El si de las niñas. Edición digital Cervantes Virtual de Juan Antonio Ríos Carratalá a partir de la de Madrid: Imprenta de Villalpando y de la de París: Aug. Bobée, 1825.

(Siglo XIX) Clarín, Leopoldo “Alas". 1900. La Regenta. Edición digital Cervantes Virtual basada en la edición de Madrid: Librería de Fernando Fé.

(Siglo XX) Laforet, Carmen. 2001. Nada. Barcelona: Bibliotex.

(Siglo XX) Lope Blanch, JuAn M. (coord.). El habla de la ciudad de México. Materiales para su estudio, México: Universidad Nacional Autónoma de México.

CORDE: Real Academia Española. Corpus diacrónico del español (CORDE) [en línea], $<$ http://www.rae.es>. Consulta: abril-junio de 2019.

\section{BIBLIOGRAFÍA}

Comer, Marie y Renata Enghels. 2017. La evolución de las perífrasis verbales causativa e incoativa con "poner" en español. Cambios de construcción y extensiones metafóricas. Bulletin of Hispanic Studies 94: 9, 903-924.

COMPANy CoMpany, CONCEPCión. 2017. El siglo XIX en la periodización sintáctica de la lengua española. En E. Carpi y R. García Jiménez (eds.). Herencia e innovación en el español del siglo XIX, pp. 75-102. Pisa: Pisa University Press.

Corominas, Joan. 1980. Diccionario crítico etimológico castellano e hispánico, con la colaboración de José A. Pascual, 6 vols. Madrid: Gredos.

De Smet, Hendrik y Olga Fischer. 2017. The role of analogy in language change: supporting constructions. En M. Hundt, S. E. Pfenninger y S. Mollin (eds.). The changing English language: Psycholinguistic perspectives, pp. 240-268. Cambridge: Cambridge University Press.

Garachana, Mar. 2011. Perífrasis sinónimas. ¿Gramaticalizaciones idénticas? Más retos para la teoría de la gramaticalización. En J. J. de Bustos Tovar, R. Cano-Aguilar, E. Méndez García de Paredes y A. López Serena (coords.). Sintaxis y análisis del discurso hablado en español: homenaje a Antonio Narbona, pp. 779-798. Sevilla: Universidad de Sevilla.

2017. Introducción. Las perífrasis verbales en una perspectiva histórica. En M. Garachana (ed.). La gramática en la diacronía. La evolución de las perifrasis verbales modales en español, pp. 9-33. Madrid/ Frankfurt: Iberoamericana Vervuert.

Garachana, Mar y Axel Hernández Díaz. En prensa. From semantics to grammar. Lexical substitution in the evolution of verbal periphrases haber/tener + infinitive. En J. Fernández Jaén y H. Provencio Garrigós (eds.). Changes in meaning and function: Studies in historical linguistics with a focus on Spanish, Amsterdam/Philadelphia: John Benjamins Publishing.

Garachana, Mar y Malte Rosemeyer. 2011. Rutinas léxicas en el cambio gramatical. El caso de las perífrasis deónticas e iterativas. Revista de Historia de la Lengua Española 6: 35-60.

HeIne, Bernd. 2003. Grammaticalization. En B. Joseph y R. Janda (eds.). The handbook of Historical Linguistics, pp. 575-601. Malden-Oxford: Blackwell.

Heine, Bernd y Tania Kuteva. 2007. The genesis of grammar. A reconstruction. Oxford: Oxford University Press.

HeRnÁNDEZ DíAz, Axel. En prensa. La perífrasis estar por + infinitivo. En M. Garachana (ed.). La evolución de las perífrasis verbales en español. Una aproximación desde la gramática de construcciones diacrónica. Bern: Peter Lang. 
Lehmann, Christian. 2015. Thoughts on grammaticalization, 3. ${ }^{a}$ ed. Berlin: Language Science Press.

Melis, Chantal y Marcela Flores. 2015. Introducción. El siglo XIX. Inicio de la tercera etapa evolutiva del español. En Ch. Melis y M. Flores (eds.). El siglo XIX. Inicio de la tercera etapa evolutiva del español, pp. 7-33. México: Universidad Nacional Autónoma de México.

Melis, Chantal, Marcela Flores y Sergio Bogard. 2003. La historia del español: propuesta de un tercer período evolutivo, Nueva Revista de Filología Hispánica 51 (1): 1-56.

Real Academia Española. En línea. Diccionario de la lengua española, actualización 2018, $<$ www.rae.es>.

En línea. Nuevo tesoro lexicográfico de la lengua española, $<\mathrm{http} / /$ buscon.rae.es/ ntlle/SrvltGUILoginNtlle>.

Rosemeyer, Malte. 2013. Tornar and volver: the interplay of frequency and semantics in compound tense auxiliary selection in Medieval and Classical Spanish. En E. van Gelderen, J. Barðdal y M. Cennamo (eds.). Argument Structure in Flux, pp. 435-458. Amsterdam/ Philadelphia: John Benjamins.

2015. Entrenchment and discourse traditions in Spanish auxiliary selection. En R. Kailuweit y M. Rosemeyer (eds.). Auxiliary Selection Revisited: Gradience and Gradualness, pp. 301-331, Berlin/ New York: De Gruyter.

Segura Munguía, Santiago. 2006. Diccionario por raices del latín y de las voces derivadas. Bilbao: Universidad de Deusto.

Traugott, Elizabeth C. 1982. From propositional to textual and expressive meanings. Some semantic-pragmatic aspects of grammaticalization. En W. P. Lehmann y Y. Malkiel (eds.). Perspectives on historical linguistics, pp. 245-272, Amsterdam: John Benjamins.

1989. On the rise of epistemic meaning in English: an example of subjectification in semantic change, Language 65 (1): 31-55.

2003. Constructions in grammaticalization. En B. D. Joseph y R. Janda (eds.). The handbook of historical linguistics, pp. 624-647. Malden/ Oxford: Blackwell. 